(c) Elsevier/INRA

Original article

\title{
Developmental temperature and somatic excision rate of mariner transposable element in three natural populations of Drosophila simulans
}

\author{
F Chakrani, P Capy *, JR David \\ Centre National de la Recherche Scientifique, Laboratoire de Biologie \\ et Génétique Evolutives, 91198 Gif-sur-Yvette Cedex, France
}

(Received 21 September 1992; accepted 12 November 1992)

Summary - The temperature effect on the somatic excision rate of an inactive copy (peach) of the mariner transposable element, inserted in the white gene and responsible of the mutation $\left(w^{p c h}\right)$, was investigated in isofemale lines from 3 natural populations of $D$ simulans. The somatic excision rate of the peach element was measured by the proportion of mosaic males in the offspring of a test-cross between a wild type male (originating from natural populations) and white peach females of a reference strain (GB1). A significant effect of the breeding temperature was detected in 2 out of the 3 populations investigated, ie Loua (Congo) and Bordeaux (France). In these 2 populations, the proportion of mosaic males increased with temperature. In the third population (Agadir, Morocco), the proportion of mosaic males was always high whatever the temperature. A slight correlation between the excision rate and the number of mariner copies was observed. Finally, this temperature effect may be related to a 14 -bp sequence localized in the $5^{\prime}$ inverted repeat of the element showing $50-57 \%$ of homology with sequences of heat shock protein promoters.

Drosophila simulans / transposable element / mariner element / temperature

Résumé - Température de développement et taux d'excision de l'élément mariner dans trois populations naturelles de Drosophila simulans. L'effet de la température sur le taux d'excision somatique d'une copie inactive (peach) de l'élément mariner, insérée dans le gène white et responsable de la mutation white peach $\left(\mathrm{w}^{\mathrm{pch}}\right)$, a été analysé dans des lignées isofemelles de 3 populations naturelles de Drosophila simulans. Le taux d'excision somatique de l'élément peach a été mesuré par le pourcentage de mâles ayant des yeux mosaïques dans la descendance des croisements entre mâles issus des populations naturelles et des femelles issues d'une lignée de référence (GB1). Un effet de la température a été décelé dans 2 populations (Loua et Bordeaux). Dans les 2 cas, le pourcentage de mâles

\footnotetext{
* Correspondence and reprints
} 
mosaïques augmente avec la température d'élevage. Dans la troisième population (Agadir), ce pourcentage est toujours élevé quelle que soit la température. Par ailleurs, bien que le taux d'excision de l'élément peach augmente avec le nombre moyen de copies de l'élément présent dans les différentes populations, une seule corrélation significative au seuil de $5 \%$ a été trouvée. Enfin, une séquence de $14 \mathrm{pb}$, située dans l'inversion répétée en $5^{\prime}$ de l'élément, présentant 50 à $57 \%$ d'homologie avec des séquences de promoteurs de protéines du choc thermique, pourrait être responsable des effets température détectés.

Drosophila simulans / élément transposable / élément mariner / température

\section{INTRODUCTION}

The genome response to environmental stresses has been investigated in many ways (Hoffmann and Parsons, 1991), and often by considering the mutator effect of various chemicals and radiations. In this context and during recent years, several authors have proposed that an environmental factor, like temperature, could modify the transcription and/or the transposition rate of transposable elements (Strand and McDonald, 1985; Junakovic et al, 1986; McDonald et al, 1987). On the other hand, populational factors, like inbreeding, could be involved in such a phenomenon. However, although Biémont et al $(1987,1990)$ showed spontaneous mobilization of copia and $P$ elements in 2 inbred lines, it cannot be assumed that consanguinity was responsible for these movements.

Among the different transposable elements described in Drosophila, a temperature effect on the excision and/or transposition rate has been demonstrated in several of them. In the $P-M$ system, hybrid dysgenesis, due to the mobility of $P$ elements, and transposase production are enhanced at high temperature (Engels, 1989 and references therein). In the $I-R$ system, the reactivity of $I$ strains is affected by temperature (Picard et al, 1977; Bucheton, 1978). Junakovic et al (1986) and Ratner et al (1992) reported an increase of transposition rate related to temperature for copia-like elements and Strand and McDonald (1985) showed an increase of copia homologous transcript after a heat shock stress. This phenomenon is not limited to Drosophila, but has also been reported in many species like Antirrhinum majus for the element Tam3 (see Coen et al, 1989 and references therein), Saccharomyces cerevisiae for the element Ty (Boeke, 1989) and Escherichia coli for the element Tn3 (Sherratt, 1989). In Drosophila, the phenomenon related to transposition, $i e$ the phenotypic effects of the transposition/excision, are stimulated when the breeding temperature increases. But, in other organisms and for other transposable elements such as Ty and Tam3, the transposition was increased at low temperature. For the first type, an interaction with promoters sensitive to temperature could exist while for the second type, it is assumed that a thermal degradation of products involved in the transposition might occur.

For the mariner element some temperature effects have already been mentioned by Garza et al (1991). Such effects were observed in a $D$ melanogaster transformed line in which the germinal excision of the non-autonomous peach element was controlled by the active element Mos1. In this line, the excision rate varied from $10.7 \%$ at $18^{\circ} \mathrm{C}$ to $26.4 \%$ at $29^{\circ} \mathrm{C}$. In $D$ simulans the same phenomenon was observed 
and the germinal excision rate of the peach element ranged from $0.2 \%$ at $18^{\circ} \mathrm{C}$ to $3.4 \%$ at $25^{\circ} \mathrm{C}$.

In the present work, we investigated the temperature effect on the somatic excision rate of an inactive element (the peach element inserted in the white gene) when induced by active elements present in isofemale lines of 3 natural populations of $D$ simulans. The general occurrence of active mariner elements was previously reported in these natural populations (Capy et al, 1990). A relationship between the average number of copies per line and the level of somatic excision was also analysed. We found a significant temperature effect for 2 of the 3 populations tested and a slightly significant overall correlation between the number of copies and the excision rate. Finally, an analysis of mariner sequence in $5^{\prime}$ of the initiation site showed a 14-bp sequence with $50-57 \%$ of homology with promoter sequence of several heat shock protein $(h s p)$ genes.

\section{MATERIALS AND METHODS}

\section{Natural populations and breeding temperature}

The 3 populations used in this work came from Loua (Congo), Agadir (Morocco) and Bordeaux (France). Season and average temperature at the time of capture are the following: for Loua, November 1989, at the end of the dry season and the begining of the wet season, the average daily temperature was $\approx 26-27^{\circ} \mathrm{C}$; for Agadir, spring 1989 with an average daily temperature of $21^{\circ} \mathrm{C}$ and Bordeaux, autumn 1989, more precisely during the vintage season and an average temperature of $17^{\circ} \mathrm{C}$. Flies were caught by attractive fermenting traps or directly by sweeping on natural breeding sites. Isofemale lines were initiated from each population ( 25 for Loua, 22 for Agadir and 31 for Bordeaux) and $<5$ generations were kept at $25^{\circ} \mathrm{C}$ in the laboratory conditions before their analysis. The isofemale line method was used to keep most of the original variability of the sample and to reduce the selection effect of laboratory conditions (Capy, 1987). The experiments were performed at 3 breeding temperatures: 17,25 and $29^{\circ} \mathrm{C}$.

\section{Somatic excisions}

The transposable element mariner can be excised either somatically or in the germline. Somatic excisions are phenotypically observed when an active element determines the excision of the non-autonomous element peach inserted in the white gene (mutation white peach, $w^{p c h}$ ). In this case, flies with mosaic eyes are observed. A mosaic eye is a white peach phenotype with 1 or several red spots (see, for example: Bryan and Hartl, 1988; Hartl, 1989). Each red spot corresponds to an excision event, and the size of a red spot is related to the excision time during the development. To quantify the rate of excision in a single individual, 4 classes of mosaic flies (Mos-0, Mos-1, Mos-2 and Mos-3) were defined according to Capy et al (1990s); see also table I for a definition of the classe. 
Table I. Percentage of mosaic flies (males) in the progeny of test-crosses between wildtype males of isofemale lines and $G B 1$ females. The $\mathrm{F}_{1}$ males are classified according to the number of independent excision events (number of red spots on both eyes) as: Mos-0 for white peach individuals (no mosaic), Mos-1, 2 and 3 phenotypes for mosaic flies with 1-6 spots, 7-20 spots and $>20$ spots respectively (Capy et al, 1990).

\begin{tabular}{lcccc}
\hline Population phenotype & \multicolumn{3}{c}{ Temperature } \\
\cline { 3 - 5 } & & $1 \gamma^{\circ} C$ & $25^{\circ} C$ & $29^{\circ} C$ \\
\hline \multirow{4}{*}{ Agadir } & $N=22$ & $N=22$ & $N=22$ \\
& Mos-0 & $20.23 \pm 3.94$ & $24.64 \pm 4.11$ & $18.87 \pm 2.97$ \\
& Mos-1 & $37.45 \pm 4.10$ & $37.68 \pm 4.88$ & $29.37 \pm 4.26$ \\
& Mos-2 & $24.68 \pm 4.14$ & $20.59 \pm 4.38$ & $20.59 \pm 4.01$ \\
& Mos-3 & $17.64 \pm 5.95$ & $17.09 \pm 6.12$ & $31.18 \pm 7.27$ \\
& & $N=30$ & $N=31$ & $N=31$ \\
Bordeaux & Mos-0 & $66.80 \pm 4.61$ & $56.48 \pm 4.84$ & $41.87 \pm 4.91$ \\
& Mos-1 & $23.70 \pm 3.06$ & $37.42 \pm 4.09$ & $38.55 \pm 4.24$ \\
& Mos-2 & $7.93 \pm 2.79$ & $3.29 \pm 0.89$ & $10.58 \pm 3.05$ \\
& Mos-3 & $1.57 \pm 1.08$ & $2.81 \pm 2.25$ & $9.00 \pm 3.70$ \\
& & $N=25$ & $N=22$ & $N=21$ \\
& Mos-0 & $85.08 \pm 2.68$ & $62.41 \pm 5.82$ & $50.48 \pm 6.78$ \\
& Mos-1 & $14.44 \pm 2.63$ & $33.27 \pm 5.80$ & $38.76 \pm 6.01$ \\
& Mos-2 & $0.28 \pm 0.16$ & $2.59 \pm 1.23$ & $5.14 \pm 1.52$ \\
& Mos-3 & $0.20 \pm 0.20$ & $1.73 \pm 0.97$ & $5.62 \pm 2.37$ \\
\hline
\end{tabular}

$N=$ number of isofemale lines.

\section{Estimation of the somatic excision rate}

The somatic excision rate, in each isofemale line, was estimated after a test-cross between 5 males of the line tested and 5 females of the GB1 strain (figure 1). The latter strain of $D$ simulans, built by Glenn Bryan (Bryan and Hartl, 1988), contains a single inactive element (the peach element) inserted in the white gene. This element was introduced in $D$ simulans from the white peach strain of $D$ mauritiana, after an interspecific cross followed by several backcrosses. The $G B 1$ strain is extremely stable and no revertant has been observed. The somatic excision rate was estimated by the ratio of mosaic males observed in the $F_{1}$ of the test-cross over the total number of $\mathrm{F}_{1}$ males examined, ie at least 10 males/line but when possible 50 males/line.

\section{Southern blots}

For each isofemale line, DNA of 25-30 individuals was prepared, as described by Junakovic et al (1984), completely digested with the restriction enzymes BamHI and HindIII, which do not cut in the element, and loaded in a single lane of a $0.8 \%$ gel agarose. To detect all elements (complete and deleted), filters were then 
Male tested Reference strain GB1

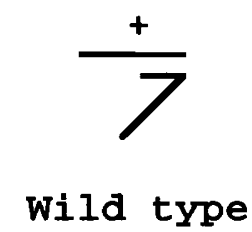

$\frac{\text { wpch }}{7}$

White peach<smiles>[TlH]</smiles>

If some excisions of the non autonomous

element peach inserted in the white gene

occur during the development (due to the

presence of autonomous element (s) in the

genome of the male tested)

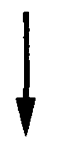

\section{Mosaic eye}

Fig 1. Test-cross used to estimate the somatic excision rate (see text for the details of the cross). The mosaic males in $F_{1}$ are classified from Mos- 0 to Mos-3 according to the number of independent excisions (number of red spots) that can be observed on both eyes.

hybridized with a mixture of the SspI-Xhol and of the Xholl-Nhel fragments of mariner (see Maruyama and Hartl, 1991). These 2 fragments cover $1.1 \mathrm{~kb}$ of the total element (total length of the element $=1.286 \mathrm{~kb}$ ). These probes were labelled by nick translation according to Maniatis et al (1982). Hybridization and washing procedures were as Junakovic et al (1984). 


\section{RESULTS}

\section{Temperature effect}

Table I gives the percentage of mosaic flies (PMF) in each population for the 3 breeding temperatures and statistical comparisons are given in table II. The 3 populations present some different PMF, the average values always being higher in Agadir than in the 2 other populations whatever the breeding temperature. A detailed analysis of table I shows that the PMF belonging to the Mos-3 class is also higher in Agadir than in Bordeaux and Loua where the Mos-0 (no mosaic) individuals are more abundant.

Table II. Analysis of variance of the percentage of mosaic flies (PMF) for the 3 natural populations.

\begin{tabular}{llrcc}
\hline Population & Source of variation & DF & Mean square & F \\
\hline Agadir & Temperature & 2 & 197 & 0.85 \\
& Line & 21 & 453 & 1.95 \\
& Residual & 42 & 232 & \\
Bordeaux & Temperature & 2 & 5158 & $14.10^{* * *}$ \\
& Line & 30 & 1370 & $3.75^{*}$ \\
& Residual & 59 & 364 & \\
Loua & Temperature & 2 & 9130 & $27.40^{* * *}$ \\
& Line & 24 & 1515 & $4.58^{*}$ \\
& Residual & 41 & 332 & \\
\hline
\end{tabular}

${ }^{*} p<0.05 ;{ }^{* * *} p<0.001$.

The PMF increases with temperature for Bordeaux and Loua but not for Agadir. The differences between the total PMF at 17 and $29^{\circ} \mathrm{C}$ are statistically significant only for the first 2 populations. Concerning Agadir, the PMF seems to be independent of the temperature. Such a result can also be due to the method used to quantify the amount of independent excisions in each individual. With this method, it is almost impossible to discriminate between individuals having a high level of somatic excision, since all of them are grouped in the Mos-3 class. In other words, it is possible that a temperature effect still existed in the Agadir population but such effect could not be quantified because the basic excision rate, in this population, remained high whatever the breeding temperature.

Table II shows that in Bordeaux and Loua both temperature and isofemale line effects were detected, but not in Agadir. Again, a more detailed analysis, class by class, showed that the temperature effect was higher in population in which the main class at $17^{\circ} \mathrm{C}$ was the Mos- 1 , ie Loua and Bordeaux. In these populations, the average number of Mos- 1 individuals decreases at $25^{\circ} \mathrm{C}$ and $29^{\circ} \mathrm{C}$, while the average number of Mos-2 and Mos-3 individuals increases. 


\section{Average number of copies per isofemale line}

The average number of copies (ANC) per isofemale line was estimated by counting the number of bands on Southern filters (fig 2). This average number includes both active and inactive copies. A large polymorphism was observed both within and between populations. In each population, it is possible to find some isofemale lines with a high or a small number of copies (see fig 2). For instance, for Agadir, line 21 presents an ANC of 17 elements while a single element was detected in line 12. The same phenomenon can be observed for the 2 other populations but the highest ANCs per line were observed for Agadir. On the other hand, it must be stressed that no line was found to be totally free of mariner, and that the average number of copies were under-estimated since co-migration of bands and degradation of high molecular weight bands may occur.

In this analysis 30,22 and 21 isofemale lines were tested for Bordeaux, Loua and Agadir, respectively, and the ANC per line are 7.9 \pm 1.2 for Agadir, $5.2 \pm 0.5$ for Bordeaux and $4.7 \pm 0.6$ for Loua. The classification of populations is the same as regards the PMF and the ANC, ie Agadir, Bordeaux and Loua, from the highest to the lowest values. Within each population, a Spearman rank correlation test between the PMF and the ANC of the different lines for each breeding temperature, showed only 1 significant correlation. Seven out of 9 coefficients were positive, but not all coefficients were independent since the numbers of mariner copies per line were used for the 3 temperatures. Therefore, although some tendencies are suggested, it remains difficult to conclude that a relationship exists between the excision rate and the number of copies in wild populations, and such a result has to be confirmed from a larger set of data.

\section{DISCUSSION AND CONCLUSION}

Our results show that in some natural populations of $D$ simulans: 1) there is a temperature effect on the somatic excision rate of an inactive copy of the mariner transposable element, 2) this temperature effect may vary from one population to another and 3) the between-population variability of the excision rate measured by the PMF could be related to the average number of mariner copies per population.

The relationship between the excision rate and the breeding temperature suggests that a promoter acting on the transposase production is sensitive to temperature. This could be an internal promoter of the transposase, included in the transposable element itself, or an external promoter, close to the insertion point of the transposable element. In this respect, the role of the genetic environment seems to be an important component of mariner element activity as already demonstrated by the position effects frequently observed (Garza et al, 1991; Maruyama et al, 1991; Medhora et al, 1991).

A comparison between the mariner sequence in $5^{\prime}$ of the initiation site and the promoter sequence of several heat shock genes was made (table III). Homology of $57 \%$ between a 14-bp sequence in the inverted repeat of the mariner transposable element and a putative promoter of $h s p-70$ was detected (see: Strand and McDonald, 1985 ; and references therein). Homologies of $50 \%$ were also observed with other 

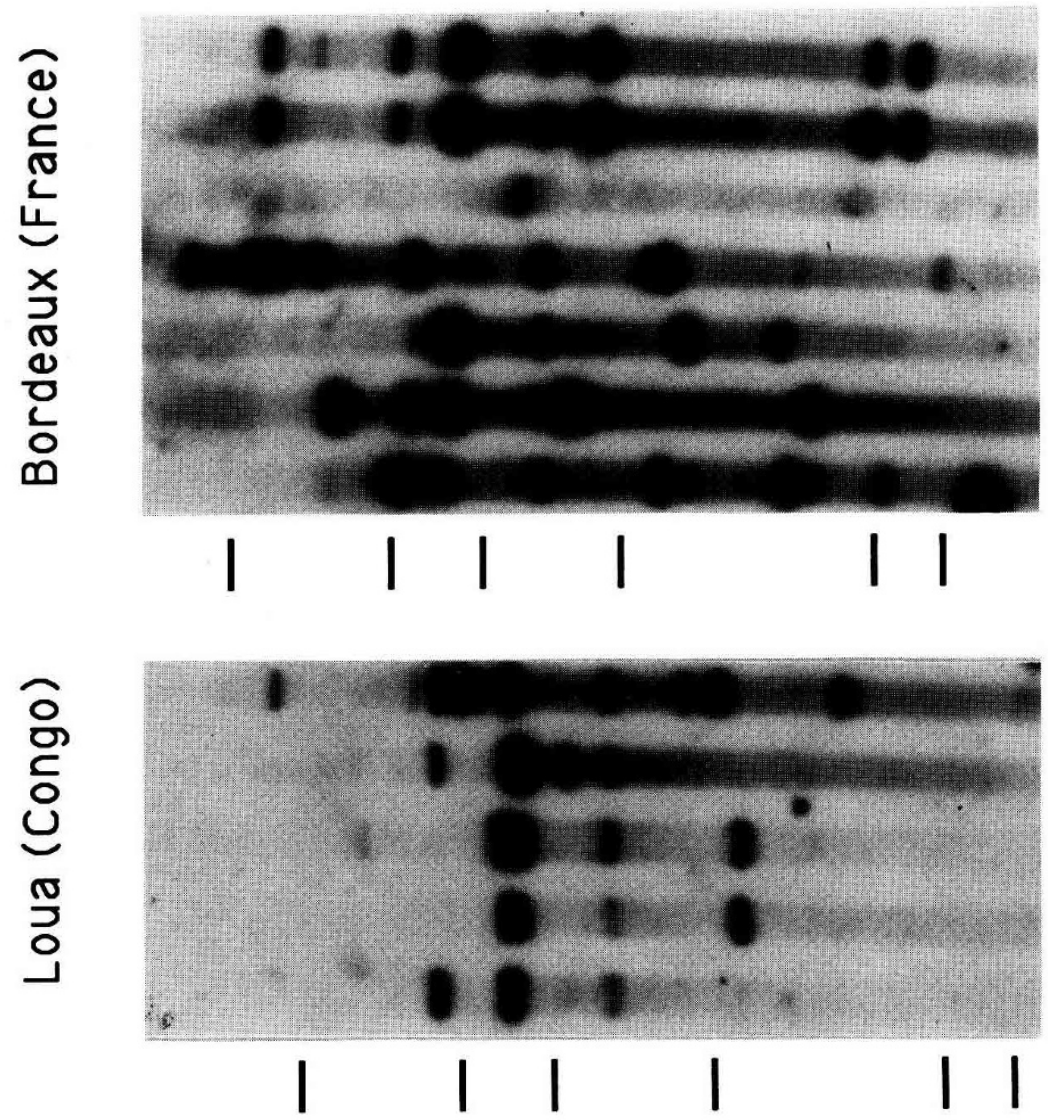

오을

○

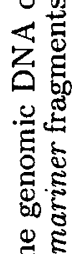

है

运吉

ฮี

退?

$\times$

起

긍

ต

을.

車要

。势学

들

क

สู

잉유

농

近范

它宾

อ ह

음뭉

0
0
0
0
0

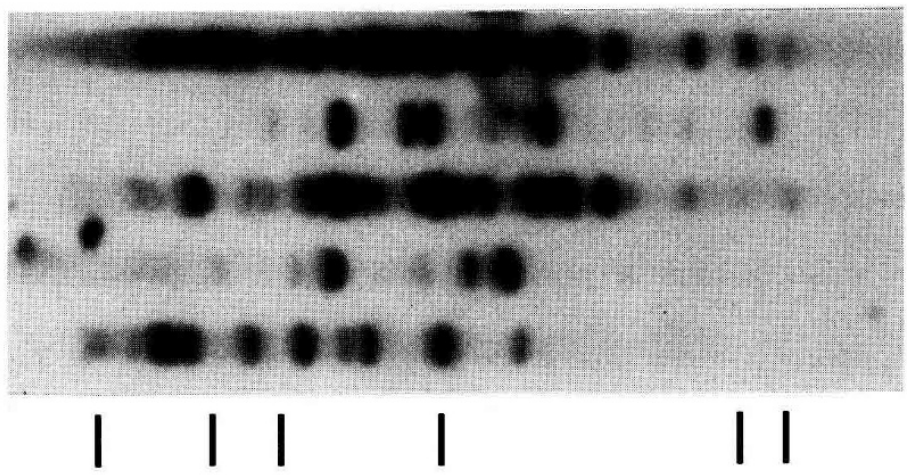

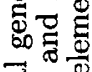

雨骂焉

选峲

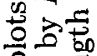

웡

돈

깅

क 원

ง

的告要 
Table III. Comparison between a 14-bp sequence localized in the $5^{\prime}$ inverted repeat (IR) of the peach element and several promoter sequences of $h s p$ and of the transposable element copia. Consensus sequence is derived from a set of $h s p$ promoter sequences given and referenced by Strand and McDonald (1985).

\begin{tabular}{llc}
\hline Gene & $\begin{array}{l}\text { Promoter } \\
\text { sequence }\end{array}$ & $\begin{array}{c}\text { Similarity } \\
\text { with peach IR (\%) }\end{array}$ \\
\hline Consensus & CTgGAAtnTTCtAG & 50 \\
$h s p-23$ & CGAGAAGTTTCGTG & 50 \\
$h s p-27$ & ATTAAGTTCCGTC & 50 \\
$h s p-68$ & CTGGAATGTTCTGA & 50 \\
$h s p-70$ & TGCGAATGTTCGCG & 57 \\
copia & TTGGAATATACTAT & 50 \\
peach & AGGGAATGTCGGTT & \\
\hline
\end{tabular}

sequences of heat shock promotors and with a 14-bp sequence of the copia transposable element (sequence localized in position - $110 \mathrm{bp}$ from the transcriptional start, $i e$ in the LTR of the element). For this latter element, a temperature effect on the transcription rate was also described (Strand and McDonald, 1985). In the case of mariner, it is thus possible that the thermosensitivity of the transcription rate is an intrinsic property of its $5^{\prime}$ inverted repeat.

Another mechanism which could explain a relationship between the breeding temperature and an excision rate would be a thermal degradation of a product involved in the repression of the element mobility. In mariner, several position effects have been described (Maruyama et al, 1991), but we do not know whether there is a positive or a negative effect of the genetic environment on the transposase production by autonomous elements. In case of a negative effect, a thermal sensitivity of a product responsible for such a repression should result in an increase of transposase production and in an increase of excision rate. For the moment, data are available on neither the transposition nor regulation mechanisms of the mariner element to test this hypothesis.

In the 3 populations investigated, our results suggest that a relationship exists between the average number of copies and the activity level of the mariner elements measured by the excision rate. Although the presence of active elements is these populations is confirmed, it is however not possible to estimate the number of active copies in each population and each isofemale line.

The activity of the mariner element may vary according to its own sequence and to its genomic position (Maruyama et al, 1991; Medhora et al, 1991; Capy et al, 1992). Therefore, a given excision rate can be due to a single element highly active or to several elements with a low activity. In this latter case, a dosage effect could exist. Such a dosage effect, for the mariner element, has already been stressed by Garza et al (1991). In the present work, it is likely that the transposable production is higher in Agadir than in Bordeaux and Loua. In other words, it is possible that Bordeaux and Loua were genetically more stable than Agadir at the moment of their sampling. 
The variability of the temperature effect observed between the three natural populations raises the following question: does this variability correspond to genetic drift between geographically distant populations or to different local adaptations?

Very few data are available on transposable elements in natural populations originating from different biogeographic areas. For numerous genetical traits, like morphological traits or enzymatic polymorphism, it seems that in $D$ melanogaster (a sibling species of $D$ simulans), an influence of the average temperature is likely for the occurrence of latitudinal clines (Lemeunier et al, 1986; David and Capy, 1988). $D$ simulans, on the other hand, generally exhibits a lower geographic differentiation, although regular latitudinal variations have been observed in several cases (Parsons, 1983; Lemeunier et al, 1986; Hoffmann and Parsons, 1991). Therefore, such a climatic factor is able to induce genetic variations among natural populations of cosmopolitan species. To detect a variability of temperature effect on excision rate of transposable elements according to the average temperature of the geographic area of natural populations, many more populations should be investigated.

In conclusion, it seems that temperature is one of the environmental factors able to induce the somatic transposition of the mariner element in natural populations of $D$ simulans. However, populations with high basic excision rate could remain insensitive to this factor.

For the moment, the data available are not sufficient to check this conclusion. But, it must be stressed again that for Drosophila, temperature is a factor which shows seasonal and daily variations in several places. Therefore, it is possible that temperature can induce genomic stresses strong enough to stimulate mobilisation and rearrangement of transposable elements. If so, the reasons and the mechanisms of these remain to be investigated.

\section{ACKNOWLEDGMENTS}

We thank J Stockel for providing the populations from France; E Pla and D Defaye for technical assistance; and 2 anonymous reviewers for helpful comments.

\section{REFERENCES}

Biémont C, Aouar A, Arnault C (1987) Genome reshuffing of the copia element in an inbred line of Drosophila melanogaster. Nature 329, 742-744

Biémont C, Arnault C, Heizmann A, Ronsseray S (1990) Massive changes in genomic locations of $P$ elements in an inbred line of Drosophila melanogaster. Naturwissenschaften 77, 485-488

Boeke JD (1989) Transposable elements in Saccharomyces cerevisiae. In: Mobile DNA (Berg DE, Howe MM, eds) Am Soc Microbiol, Washington, DC, 335-374

Bryan G, Hartl DL (1988) Maternally inherited transposon excision in Drosophila simulans. Science 240, 215-217

Bucheton A (1978) Non-Mendelian female sterility in Drosophila melanogaster: influence of aging and thermic treatments. Heredity 41, 357-369

Capy P (1987) Variabilité génétique des populations naturelles de Drosophila melanogaster et de Drosophila simulans. Thèse Univ Paris XI, 217 pp 
Capy P, Chakrani F, Lemeunier F, Hartl DL, David JR (1990) Active mariner transposable elements are widespread in natural populations of Drosophila simulans. Proc $R$ Soc Lond $B$ 242, 57-60

Capy P, Koga A, David JR, Hartl DL (1992) Sequence variation among active mariner elements in natural populations of Drosophila simulans. Genetics 130, 499506

Coen E, Robbins TP, Almeida J, Hudson A, Carpenter R (1989) Consequences and mechanisms of transposition in Antirrhinum majus. In: Mobile DNA (Berg DE, Howe MM, eds) Am Soc Microbiol, Washington DC, 413-436

David JR, Tsacas (1981) Cosmopolitan, subcosmopolitan and widespread species: different strategies within the Drosophilid family (Diptera). CR Soc Biogeog 57, 11-26

David JR, Capy P (1988) Genetic differentiation of Drosophila melanogaster natural populations. Trends Genet 4, 106-111

David JR, Capy P, Payant V, Tsakas S (1985) Thoracic trident pigmentation in Drosophila melanogaster: differentiation of geographical population. Genet Sel Evol 17, 211-224

David JR, Alonso-Moraga A, Borai F, Capy P, Mercot H, McEvey S, MunozSerrano A, Tsakas SC (1989) Latitudinal variation of $A d h$ gene frequencies in Drosophila melanogaster: a Mediterranean instability. Heredity 62, 11-16

Engels WR (1989) $P$ element in Drosophila melanogaster. In: Mobile DNA (Berg DE, Howe MM, eds) Am Soc Microbiol, Washington DC, 437-484

Garza D, Medhora M, Koga A, Hartl DL (1991) Introduction of the transposable element mariner into the germline of Drosophila melanogaster. Genetics 128, 303310

Hartl DL (1989) Transposable element mariner in Drosophila species. In: Mobile DNA (Berg DE, Howe MM, eds) Am Soc Microbiol, Washington, DC, 531-536

Hoffmann AA, Parsons PA (1991) Evolutionary Genetics and Environmental Stress. Oxford Univ Press, Oxford

Junakovic N, Caneva R, Balario P (1984) Genomic distribution of copia-like elements in laboratory stocks in Drosophila melanogaster. Chromosoma 90, 378382

Junakovic N, Di Franco C, Barsanti P, Palumbo G (1986) Transposition of copia-like nomadic elements can be induced by heat shock. J Mol Evol 24, 89-93

Lemeunier F, David JR, Tsacas L, Ashburner M (1986) The melanogaster species group. In: The Genetics and Biology of Drosophila (Ashburner M, Carson HL, Thompson Jr JN, eds) Acad Press, New York, vol 3B, 148-239

Maniatis T, Fritsch EF, Sambrook J (1982) Molecular Cloning: A Laboratory Manual. Cold Spring Harbor Laboratory, New York

Maruyama K, Schoor KD, Hartl DL (1991) Identification of nucleotide substitutions necessary for trans-activation of mariner transposable elements in Drosophila: analysis of naturally occurring elements. Genetics $128,777-784$

Maruyama K, Hartl DL (1991) Evolution of the transposable element mariner in Drosophila species. Genetics 128, 319-329

McDonald JF, Strand DJ, Lambert ME, Weinstein IB (1987) The responsive genome: evidence and evolutionary implications. In: Development as Evolutionary Process (Rauff R, Rauff E, eds) Alan R Liss, New York 
Medhora M, Maruyama K, Hartl DL (1991) Molecular and functional analysis of the mariner mutator element Mos1 in Drosophila. Genetics 128, 311-318

Parsons (1983) The Evolutionary Biology of Colonizing Species. Cambridge Univ Press, Cambridge

Picard G, Lavigne JM, Bucheton A, Bregliano JC (1977) Non-Mendelian female sterility: physiological pattern of embryo lethality. Biol Cell 29, 89-98

Ratner VA, Zabanov SA, Kolesnikova OV, Vasilyeva LA (1992) Induction of the mobile genetic element $D m-412$ transpositions in the Drosophila genome by heat shock treatment. Proc Natl Acad Sci USA 89, 5650-5654

Strand J, McDonald JF (1985) Copia is transcriptionally responsive to environmental stress. Nucleic Acids Res 13, 4401-4410

Sherratt D (1989) Tn3 and related transposable elements: site-specific recombination and transposition. In: Mobile DNA (Berg DE, Howe MM, eds) Am Soc Microbiol, Washington, DC, 163-184 